\title{
Study of the Electrical Characteristics, Shock-Wave Pressure Characteristics, and Attenuation Law Based on Pulse Discharge in Water
}

\author{
Dong Yan, Decun Bian, Jinchang Zhao, and Shaoqing Niu \\ College of Mining Engineering, Taiyuan University of Technology, Taiyuan 030000, China \\ Correspondence should be addressed to Jinchang Zhao; jinchangprofessor@163.com
}

Received 9 March 2016; Accepted 11 May 2016

Academic Editor: Isabelle Sochet

Copyright @ 2016 Dong Yan et al. This is an open access article distributed under the Creative Commons Attribution License, which permits unrestricted use, distribution, and reproduction in any medium, provided the original work is properly cited.

\begin{abstract}
Strong shock waves can be generated by pulse discharge in water. Study of the pressure characteristics and attenuation law of these waves is highly significant to industrial production and national defense construction. In this research, the shock-wave pressures at several sites were measured by experiment under different conditions of hydrostatic pressure, discharge energy, and propagation distance. Moreover, the shock-wave pressure characteristics were analyzed by combining them with the discharge characteristics in water. An attenuation equation for a shock wave as a function of discharge energy, hydrostatic pressure, and propagation distance was fitted. The experimental results indicated that (1) an increase in hydrostatic pressure had an inhibiting effect on discharge breakdown; (2) the shock-wave peak pressure increased with increasing discharge voltage at $0.5 \mathrm{~m}$ from the electrode; it increased rapidly at first and then decreased slowly with increasing hydrostatic pressure; and (3) shock-wave attenuation slowed down with increasing breakdown energy and hydrostatic pressure during shock-wave transfer. These experimental results were discussed based on the mechanism described.
\end{abstract}

\section{Introduction}

Controllable high energy can be released during an instantaneous high-voltage pulse discharge in water [1]. The phenomenon is similar to an explosion, has huge engineering potential, and has been widely used in many fields such as resource prospecting, oil extraction, gas processing, and national defense construction $[2,3]$. The breakdown channel of a high-voltage pulse discharge in water generates plasma and rapidly releases a huge amount of energy to form the shock wave [4]. The shock-wave pressure and attenuation law during propagation is an important topic of study for understanding high-voltage pulse discharges in water with different discharge energies and hydrostatic pressures. Moreover, this phenomenon is also widely used in engineering. Shock waves in water have been investigated before [5-7]. However, the pressure load characteristics and attenuation law of shock waves propagating in water with different hydrostatic pressures have not been systematically studied. Therefore, the simultaneous influence of discharge energy and hydrostatic pressure on shock waves needs to be more deeply investigated.

\section{Experimental}

2.1. Fundamental Physical Process. During the breakdown of a water dielectric by a high-voltage pulse discharge, the liquid phase-gas phase-plasma transformation is finished within a very short time, forming a high-temperature, high-pressure plasma channel. The huge pressure gradient in the channel due to the high pressure inside and the temperature gradient at the plasma boundary leads to rapid outward expansion of the plasma channel, which achieves a high-speed transformation from electrical to mechanical energy [8]. Because the compressibility of water around the plasma channel is weak, its mechanical energy is mainly released outward in the form of a wave. The generated high-energy wave is called a shock wave.

The shock-wave peak pressure depends on various factors including discharge energy, distance to the electrode, and 


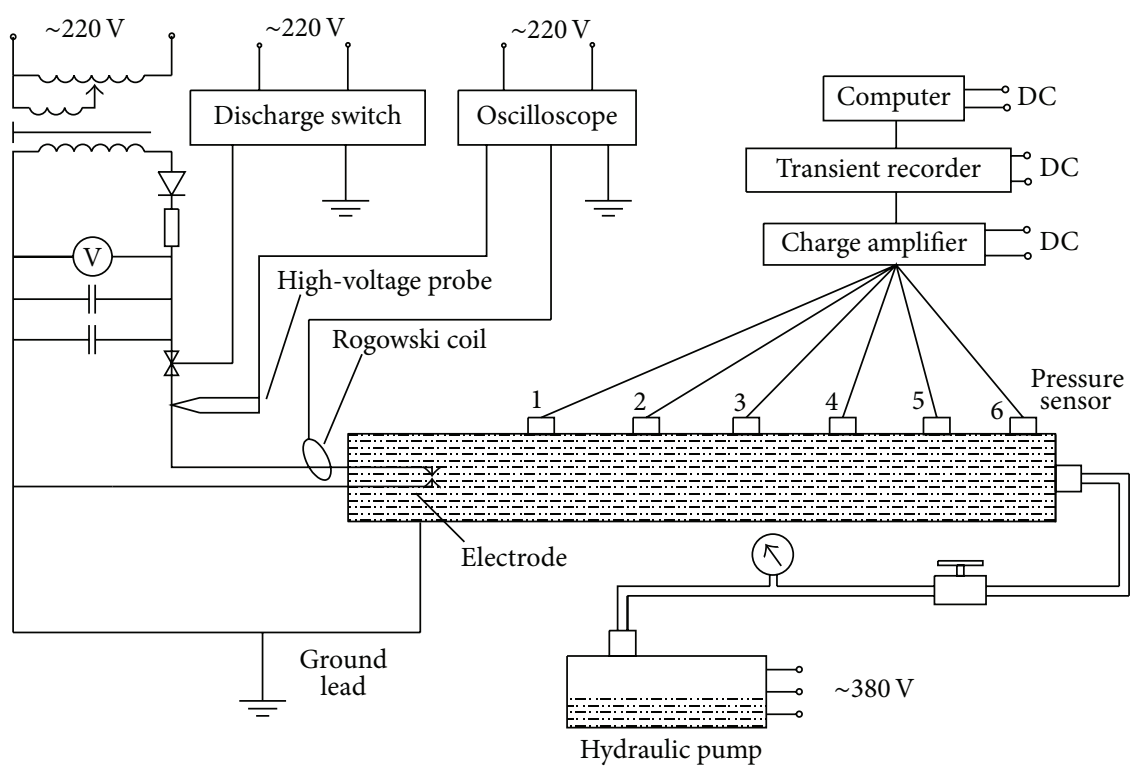

FIGURE 1: Schematic diagram of experimental device.

hydrostatic pressure. The shock wave is the carrier that transfers the discharge energy in water, and hence the shockwave peak pressure is directly affected by the discharge energy. Meanwhile, the measured peak pressure is inevitably different at different distances from the wave source due to energy attenuation of the shock wave during its propagation in water. In addition, the damping effect of water is influenced by hydrostatic pressure, which has a direct influence on the formation of the initial shock wave. Moreover, the extent of shock-wave attenuation during propagation varies with the hydrostatic pressure of the water dielectric [9].

The pressure characteristics and attenuation law of shock waves in water are affected by three main factors: discharge energy, hydrostatic pressure, and propagation distance. This relation can be expressed in function form as $P=f\left(E_{b}, P_{w}, d\right)$, where $P$ is the shock-wave peak pressure, $E_{b}$ is the discharge breakdown energy of the water dielectric, $P_{w}$ is the hydrostatic pressure, and $d$ is the distance from the shock wave to the discharge electrode. In this research, the corresponding parameters related to hydrostatic pressure were further introduced into the function expression above based on previous studies of shock waves in water. Shockwave attenuation during propagation was analyzed systematically under different hydrostatic pressure conditions.

2.2. Experimental Equipment. The experimental equipment was composed of the experimental device and the system for measuring the pulse discharges in water. The experimental device for measuring pulse discharges in water is shown schematically in Figure 1. The self-triggering discharge switch, shown in Figure 2, can effectively reduce errors caused by artificial triggering. The pulse power supply provided DC at high voltage in the $6 \mathrm{KV}-15 \mathrm{KV}$ range. The rated capacitance was $60 \mu \mathrm{F}$, and the energy storage limit was $7000 \mathrm{~J}$. The electrodes were made of coaxial steel tube and copper bar. A schematic diagram and photograph of the electrode structure

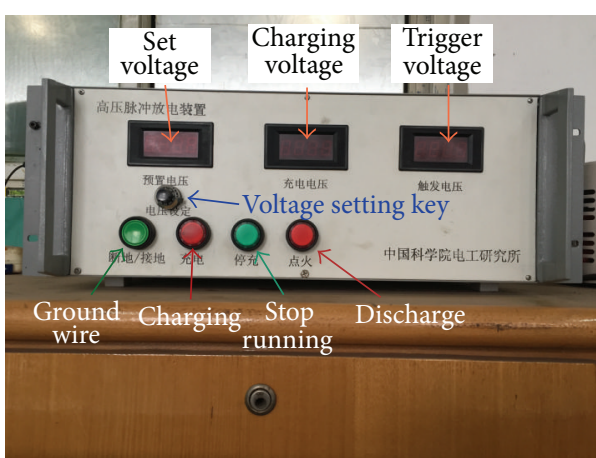

The appearance of discharge switch

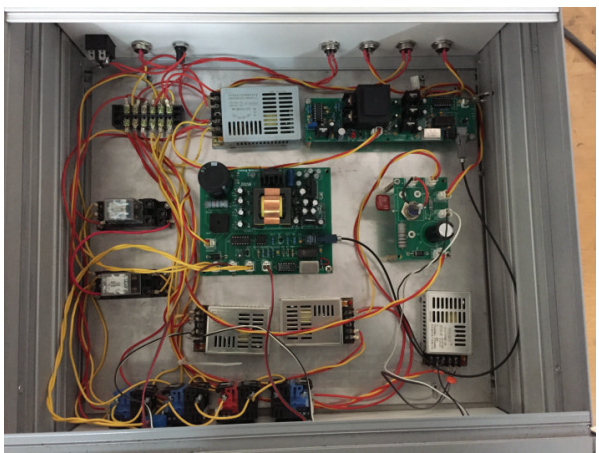

The internal structure of discharge switch

FIGURE 2: Self-triggering discharge switch.

are shown in Figure 3. The space between the positive and negative electrodes was $5 \mathrm{~mm}$. The electrodes were located at the end of a tube with an inner diameter of $100 \mathrm{~mm}$ and a length of $4 \mathrm{~m}$. Six sensor connectors were uniformly distributed on one side of the tube wall, $500 \mathrm{~mm}$ apart. The distance from the electrode to the nearest (number 1) sensor connector was also $500 \mathrm{~mm}$. The tube was filled with tap water with 

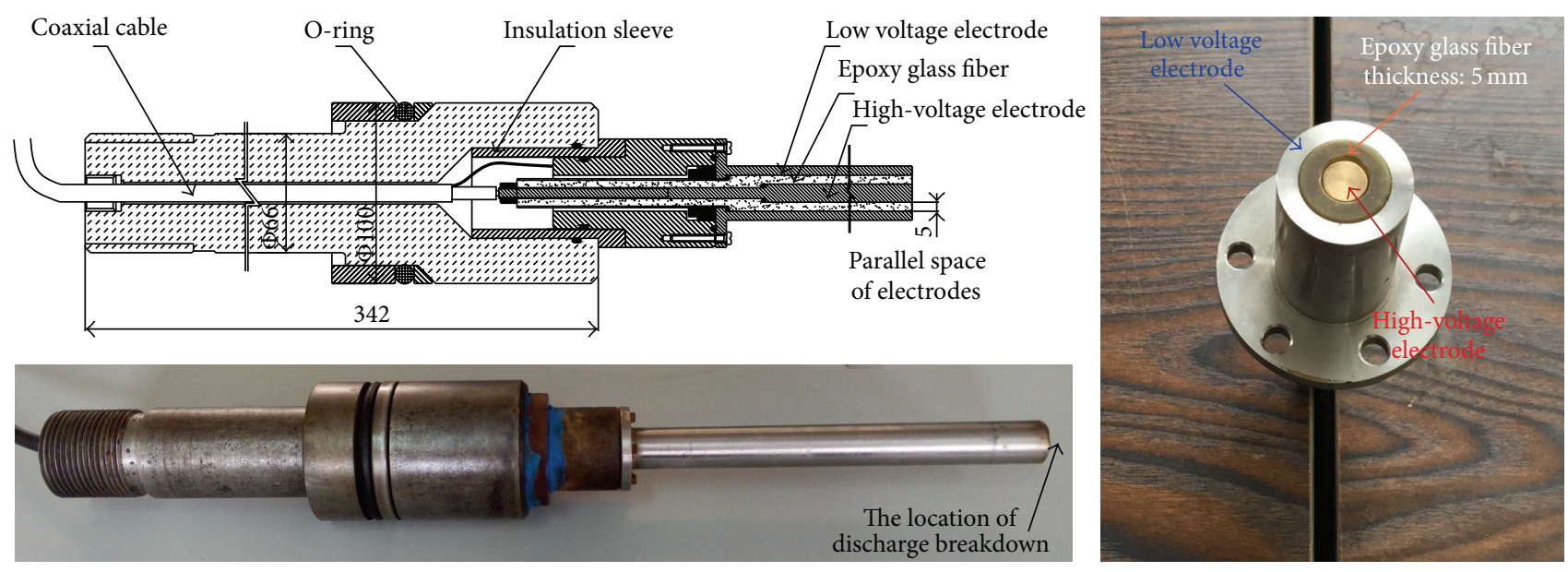

FIGURE 3: Schematic diagram and photograph of electrode structure.

a conductivity of about $1.3 \mathrm{~S} / \mathrm{m}$. The pre-set hydrostatic pressure was adjusted by an external hydraulic pump with a maximum capacity of $12 \mathrm{MPa}$.

The measuring system in this study was composed of seven parts: a Rogowski coil, a P6015A high-voltage probe, a DSO6014A oscilloscope, piezoelectric pressure sensors, a charge amplifier, a signal recorder, and a computer. The sensitivity of the Rogowski coil was $38 \mathrm{KA} / \mathrm{V}$, and it was suitable for measuring pulse current due to its high measurement precision [10]. The P6015A high-voltage probe could meet the acquisition accuracy for transient voltage [11]: the maximum input voltage was $20 \mathrm{kV}$, the bandwidth was $75 \mathrm{MHz}$, the rise time was $4.0 \mathrm{~ns}$, and the compensation range was $7-49 \mathrm{pF}$. The sampling rate of the DSO6014A oscilloscope was $4 \mathrm{GSa} / \mathrm{a}$. The piezoelectric pressure sensor was a CY-214 model with a range of $200 \mathrm{MPa}$. The charge amplifier was a YE5853 model with a bandwidth of $2 \mu \mathrm{Hz}-100 \mathrm{KHz}$. The signal recorder was a YE6231 model with a sampling frequency of $96 \mathrm{KHz}$.

2.3. Experimental Scheme. The capacitance of the high-voltage pulse power supply was constant at $60 \mu \mathrm{F}$. The discharge voltage and hydrostatic pressure were variables in this study. The shock-wave pressures at the six sensor connectors were measured. The effects of discharge energy, hydrostatic pressure, and distance on the pressure characteristics and attenuation of the shock wave were investigated. The whole tube was completely filled with water. The external hydrostatic pressure was classified into seven levels: $0,1,2,3,4,6$, and $8 \mathrm{MPa}$. The charging voltage $\left(U_{m}\right)$ was classified into six levels: $8,9,10$, 11,13 , and $15 \mathrm{KV}$. A total of 42 groups of independent experiments were conducted under different hydrostatic pressure and voltage conditions (seven levels for hydrostatic pressure and six levels for voltage). Five discharge tests were performed for each group of experiments.

The measurement of discharge energy and shock-wave peak pressures at each site were important constituents of this study. If the breakdown energy of the water dielectric by high-voltage discharge was directly calculated using the formula $E=(1 / 2) C U^{2}$ (where $E$ is the discharge energy, $C$ is the capacitance, and $U$ is the charging voltage), the results would be larger. Due to the influence of water conductivity, residual capacitance energy, and circuit energy loss, the actual breakdown energy of the water dielectric was determined by the specific breakdown voltage $[12,13]$. Therefore, a highprecision current test coil and a high-voltage probe were used in this study to measure the transient current and voltage during the whole breakdown process of the water dielectric. The actual discharge energy involved in breaking down the water dielectric was thus obtained.

The shock-wave peak pressure at each site was collected by the sensor. To reduce the interference of electromagnetic waves and stray currents on the sensor during the highvoltage discharge, the sensor base was made of nylon materials to insulate it effectively from the influence of stray currents at the tube wall. A $1 \mathrm{~mm}$ thick lead protective cover was used to prevent the electromagnetic waves from interfering with the sensor and the acquisition equipment. The shock-wave pressure data were transmitted to the signal recorder through the charge amplifier and displayed synchronously on the computer. The whole acquisition system ran on DC power to avoid the conduction coupling interference of each part formed by the power supply during the high-voltage discharge [14].

Hydrostatic pressure in the tube was provided by the external hydraulic pump. The precision of this equipment was high, with good pressure stability. The bearing pressure of the whole experimental apparatus could be as high as $12 \mathrm{MPa}$.

\section{Pulse Discharge Characteristics in Water}

During breakdown of the water dielectric by electrode discharge, a large amount of energy was released within a very short time. In this process, the measurement of transient current and transient voltage could accurately reflect the highvoltage pulse discharge characteristics. The transient current and the transient voltage were measured and collected using an oscilloscope. The charging voltage was $11 \mathrm{KV}$, and the hydrostatic pressure was $1 \mathrm{MPa}$. The yellow curve in Figure 4 represents the current function $I(t)$, and the green curve in Figure 5 represents the voltage function $U(t)$. In addition, 


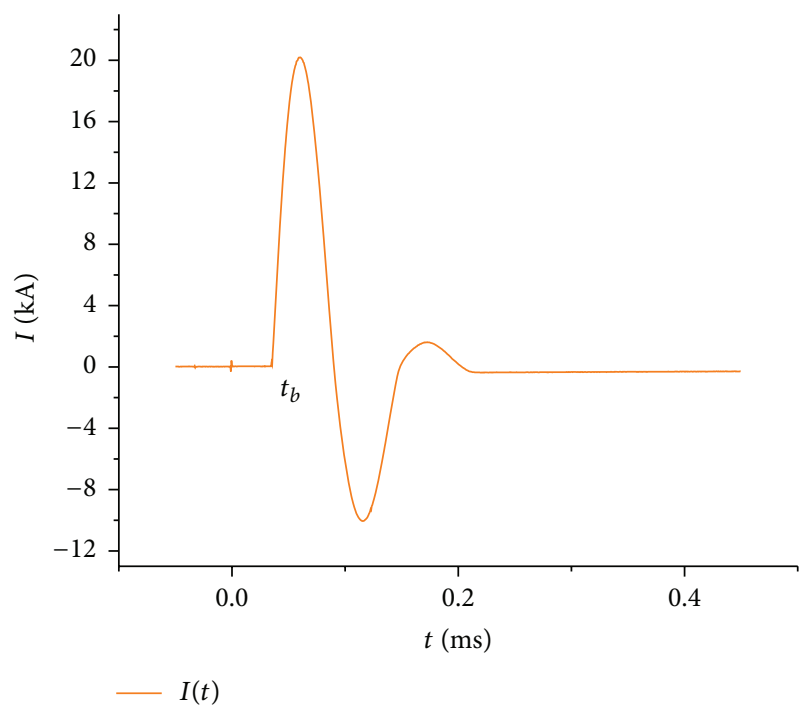

FIgURE 4: Time-history curve of discharge current $I(t)$.

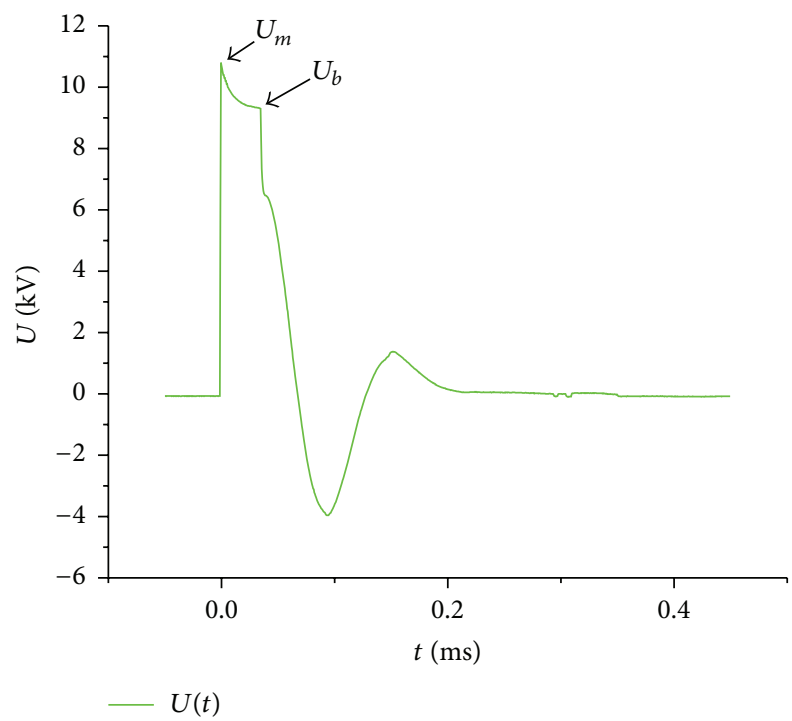

FIGURE 5: Time-history curve of discharge voltage $U(t)$.

the maximum charging voltage $\left(U_{m}\right)$, the breakdown voltage $\left(U_{b}\right)$, and breakdown time $\left(t_{b}\right)$ are also marked.

The discharge process can be described as follows: the discharge starts when the capacitor is charged to the rated voltage. The maximum charging voltage $\left(U_{m}\right)$ decreases slowly before breakdown of the water dielectric due to the influence of conductivity. The voltage decreases greatly at the moment of breakdown of the water dielectric. Then the voltage decreases as the current increases, and electrical energy is rapidly released into the breakdown channel. The breakdown voltage $\left(U_{b}\right)$ is the remanent voltage in capacitor at the moment of breakdown of the water dielectric by arc discharge. This time is referred to as the breakdown time $\left(t_{b}\right)$ (the moment of discharge was time 0). Among the high-voltage pulse discharge characteristics, the breakdown voltage $\left(U_{b}\right)$ is the major factor determining the breakdown

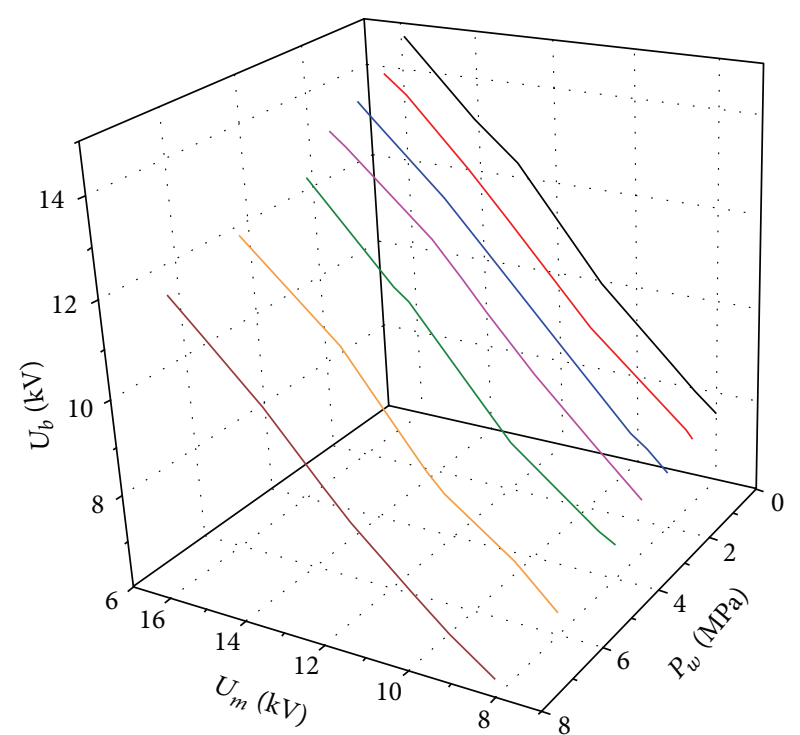

FIGURE 6: Plot between charging voltage $\left(U_{m}\right)$ and breakdown voltage $\left(U_{b}\right)$ under different hydrostatic pressure $\left(P_{w}\right)$ conditions.

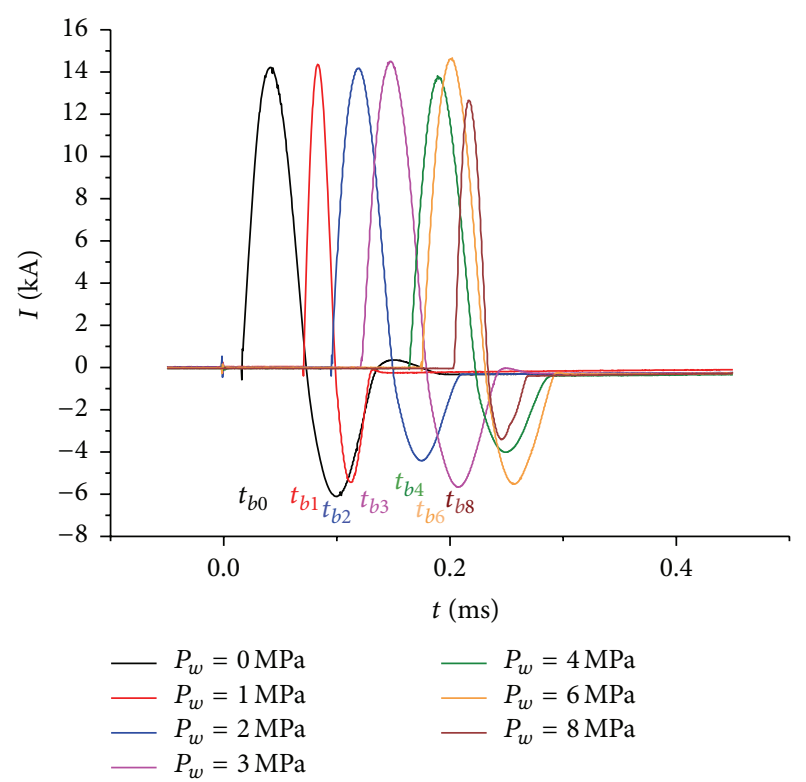

FIGURE 7: Plot of $I(t)$ and $t_{b}$ with a charging voltage of $8 \mathrm{KV}$ and different hydrostatic pressures.

energy $\left(E_{b}\right)$ of the water dielectric, and it directly influences shock-wave formation.

Hydrostatic pressure in this study was classified into seven levels from $0 \mathrm{MPa}$ to $8 \mathrm{MPa}$. Different $U_{b}$ values were obtained by adjusting $U_{m}$. The measurement results are shown in Figure 6.

The breakdown voltage $\left(U_{b}\right)$ was the result measured by experiments. It can be also deduced and verified by electrical formulas. Figure 7 presents the current waveform and breakdown time $\left(t_{b}\right)$ under different hydrostatic pressure conditions for a charging voltage of $8 \mathrm{KV}$. 
Figure 7 shows that the high-voltage pulse discharge is determined by the differential equation of the RLC circuit [15]:

$$
\frac{L d i}{d t}+R(t) i+\left(\frac{1}{C}\right) \int i d t=0,
$$

where $L$ is the lead inductance, which is a small constant; $C$ is the rated capacitance; and $C=60 \mu \mathrm{F}$. The electrode spacing was $5 \mathrm{~mm}$, and the conductivity of tap water was $\gamma=1.3 \mathrm{~S} / \mathrm{m}$. The equivalent resistance $R(t)$ is preliminarily determined by initial voltage and liquid conductivity and can be expressed as $R=R_{c}+R_{w}$, where $R_{c}$ is the pure resistance of the circuit and is very small, and $R_{w}$ is the equivalent resistance between the electrodes, which can be expressed by a time-varying second-order homogeneous differential equation. An accurate numerical solution could be obtained, and the calculation results were all within $0.2 \Omega$ [16]. The relationship between breakdown voltage and breakdown time could be expressed as [17]

$$
U_{b}^{\prime}=U_{m} e^{-t_{b} / R C} .
$$

Equation (2) states that $U_{b}^{\prime}$ can be obtained from the charging voltage $\left(U_{m}\right)$, the breakdown time $\left(t_{b}\right)$, and the resistance $(R)$. The breakdown voltage $\left(U_{b}\right)$ actually measured was compared to the calculated value $U_{b}^{\prime}$. It was found that the measured $U_{b}$ was very close to $U_{b}^{\prime}$, with deviations of less than $10 \%$.

The experimental results indicated that the breakdown voltage $\left(U_{b}\right)$ increased with increasing charging voltage $\left(U_{m}\right)$. $U_{m}$ and $U_{b}$ showed an approximately linear relationship. Moreover, the higher the charging voltage, the smaller the attenuation of the breakdown voltage, as shown in Figure 6. The reason can be explained as follows: with an increase in charging voltage, both breakdown time and breakdown channel resistance decreased, whereas the peak current of the circuit increased. For the experimental electrodes, the relationship between discharge end field strength and electrode end voltage can be expressed as [17]

$$
E_{S} \approx U r \ln \frac{2 l}{r},
$$

where $r$ is the end curvature radius of the electrode; $U$ is the end voltage of the electrode, called the charging voltage $\left(U_{m}\right)$; $I$ is the gap distance; and $E_{S}$ is the end electric field strength. The end field strength of the electrode $\left(E_{S}\right)$ increases with increasing charging voltage $\left(U_{m}\right)$. As for the breakdown time of the water dielectric, the qualitative theory and empirical equation [18] (Martin equation) for breakdown field strength in a water dielectric can be referenced:

$$
E_{c}=\frac{K}{A^{\alpha} t^{\beta}},
$$

where $E_{c}$ is the breakdown field strength; $A$ is the effective area of the electrode; $t$ is the breakdown time; $\alpha, \beta$, and $K$ are constants related to the discharge process, and $\alpha, \beta$, and $K>0$.
When the voltage meets the breakdown requirements of a water dielectric, that is, $E_{S}=E_{c}$, the following equation can be obtained by combining (3) and (4):

$$
t=\sqrt[\beta]{\frac{K}{A^{\alpha} U r \ln (2 l / r)}} .
$$

It is apparent that the breakdown time $(t)$ definitely decreases with increasing voltage $(U)$ when other constants are fixed.

The increase in charging voltage $\left(U_{m}\right)$ enhances the field strength difference between the two ends of the water gap and accelerates the ionization and gasification velocity of the water dielectric. As a result, the rapid formation of avalanche ionization is expedited, leading to a decrease in breakdown time $\left(t_{b}\right)$.

Equation (2) shows that the breakdown voltage $\left(U_{b}\right)$ increases when the breakdown time $\left(t_{b}\right)$ is reduced. Moreover, the higher the charging voltage $\left(U_{m}\right)$, the shorter the breakdown time and the less the attenuation from $U_{m}$ to $U_{b}$. These experimental results are consistent with the inference when the hydrostatic pressure was fixed.

When the charging voltage $\left(U_{m}\right)$ was fixed, the breakdown voltage $\left(U_{b}\right)$ showed an obvious decreasing trend with increasing hydrostatic pressure. Meanwhile, consuming electrical energy was increased before discharge breakdown of the water dielectric; therefore the breakdown energy $\left(E_{b}\right)$ in the whole breakdown process decreased significantly. The increase in hydrostatic pressure resulted in increases in breakdown channel resistance and breakdown time $\left(t_{b}\right)$. The experimental results are shown in Figure 7. The breakdown time increased with increasing hydrostatic pressure. Therefore, the hydrostatic pressure exhibited an inhibiting effect on the discharge breakdown process [19].

The attenuation of breakdown voltage $\left(U_{b}\right)$ was slow when the hydrostatic pressure was in the range of $0-3 \mathrm{MPa}$. The influence of hydrostatic pressure on the breakdown process was small. The attenuation increased suddenly when the hydrostatic pressure reached $4 \mathrm{MPa}$. After this, the attenuation tended towards stability. In this study, the experimental equipment was filled with tap water, and there were many small bubbles on the electrode surface and in the water [20]. The required breakdown field strength of the electrode was not high due to the presence of bubbles, and therefore the energy loss before breakdown was small. When the hydrostatic pressure was in the range of $0-3 \mathrm{MPa}$, the small bubbles in the water were gradually removed by hydrostatic pressure. Due to the presence of these small bubbles, the hindering effect of hydrostatic pressure on discharge breakdown was inhibited. As a result, the breakdown voltage $\left(U_{b}\right)$ decreased slowly with increasing hydrostatic pressure. When the hydrostatic pressure exceeded a certain value (4 MPa in this study), the original small bubbles in the water had disappeared. The inhibiting effect of hydrostatic pressure, which had hindered the formation of the breakdown channel, was lost, and hence the breakdown voltage $\left(U_{b}\right)$ decreased greatly.

The breakdown energy $\left(E_{b}\right)$ was the key factor in shockwave generation and also an indispensable parameter in the study of shock-wave features. The breakdown energy $\left(E_{b}\right)$ 


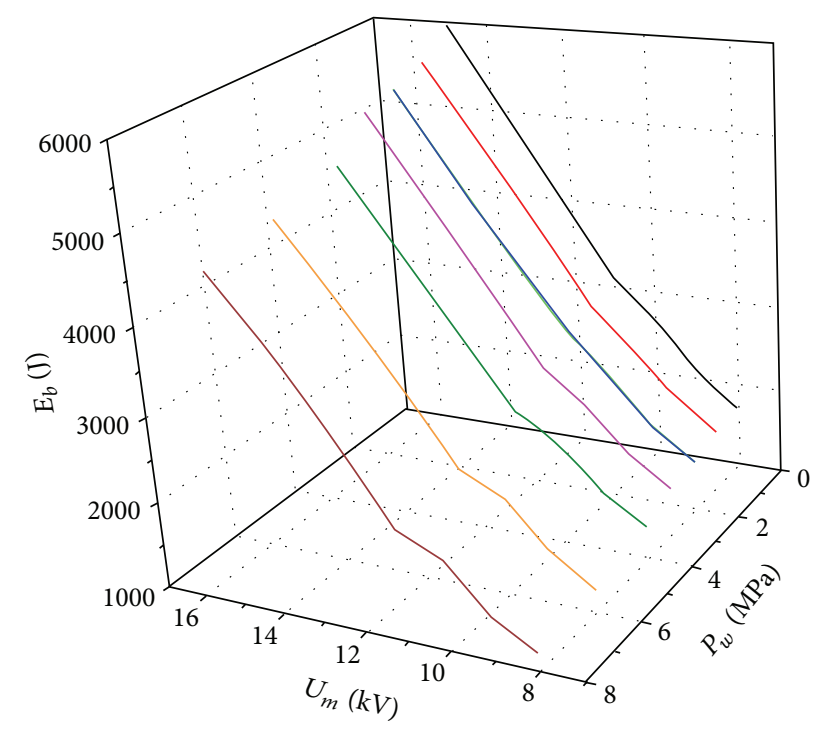

FIGURE 8: Plot of charging voltage $\left(U_{m}\right)$ and breakdown energy $\left(E_{b}\right)$ under different hydrostatic pressure $\left(P_{w}\right)$ conditions.

input into the discharge gap at the moment of breakdown was $E_{b}=C U_{b}^{2} / 2$. The results are shown in Figure 8.

\section{Pressure Characteristics and Attenuation Law of Shock Waves}

4.1. Pressure Characteristics of Shock Waves. When a shock wave is generated, energy is instantly injected into the plasma channel at the moment of high-voltage pulse discharge and then rapidly diffused all around. The surrounding water dielectric is strongly extruded, resulting in rapid increases in pressure, density, and temperature. As a result, the initial shock wave is generated. This study focuses on the relationship between breakdown energy $\left(E_{b}\right)$, hydrostatic pressure $\left(P_{w}\right)$, and shock-wave peak pressure $(P)$. The position of number 1 sensor, which was nearest to the electrode, was selected as the collection point for shock-wave pressure characteristics. The distance between number 1 sensor and the electrode was $0.5 \mathrm{~m}$. The shock-wave peak pressure at $0.5 \mathrm{~m}$ was measured under the pre-set conditions of charging voltage and hydrostatic pressure. The results are shown in Figure 9 , where $P_{w}$ is the hydrostatic pressure and $P$ is the shock-wave peak pressure.

4.1.1. Influence of Breakdown Energy $\left(E_{b}\right)$ on Shock-Wave Pressure Characteristics. The charging voltage $\left(U_{m}\right)$ in Figure 8 corresponds to the breakdown energy $\left(E_{b}\right)$, whereas the charging voltage $\left(U_{m}\right)$ in Figure 9 corresponds to the shock-wave peak pressure $(P)$. When the charging voltage $\left(U_{m}\right)$ increases, the breakdown energy $\left(E_{b}\right)$ increases, and the shock-wave peak pressure $(P)$ also increases. Because the breakdown time is reduced with increasing charging voltage $\left(U_{m}\right)$, the energy leakage from discharge to breakdown decreases. Consequently, the energy input into the plasma channel increases, which enhances the shock-wave peak pressure. According to the theory of shock waves in water

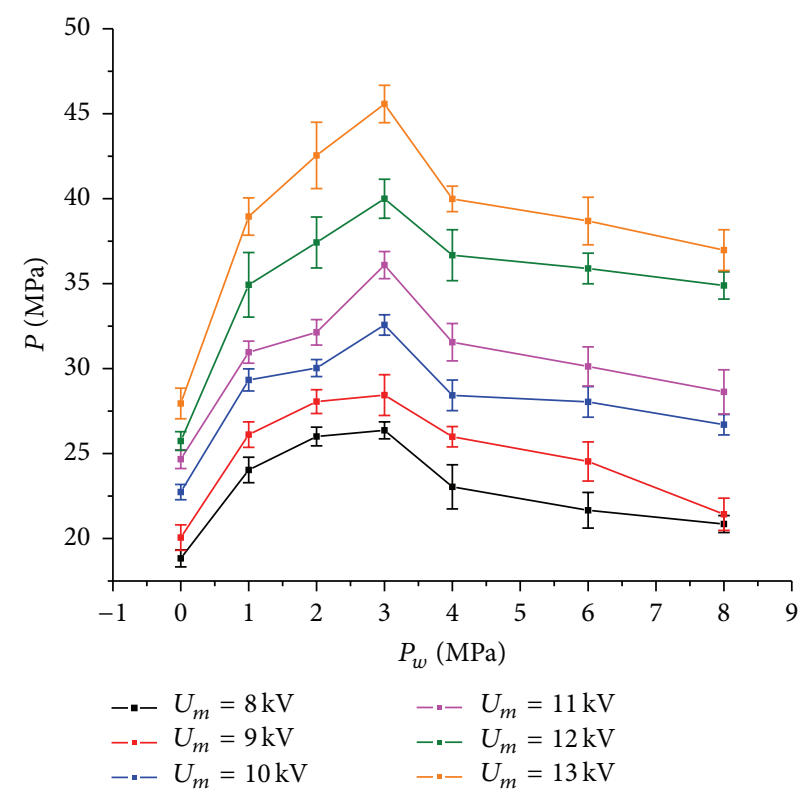

FIGURE 9: Plot of shock-wave peak pressure at $0.5 \mathrm{~m}$.

proposed by Touya et al., the shock-wave peak pressure can be expressed by the following empirical equation [21]:

$$
P=\left(9000 \cdot d^{-1}\right) \cdot E_{b}^{\alpha},
$$

where $P$ is the shock-wave peak pressure; $d$ the distance from the electrode to the sensor, $\mathrm{mm} ; E_{b}$ is the breakdown voltage during discharge; and $\alpha$ is the shock-wave transfer constant. Equation (6) states that higher energy $E_{b}$ leads to higher shock-wave peak pressure when $\alpha$ is a constant. For example, when the hydrostatic pressure was $0 \mathrm{MPa}$, the corresponding breakdown energy values $\left(E_{b}\right)$ were $1696.5,2086.6,2656.4$, $3078.5,4523.9$, and $5905.8 \mathrm{~J}$ for charging voltages $\left(U_{m}\right)$ of 8,9 , $10,11,13$, and $15 \mathrm{KV}$, respectively. The corresponding shockwave peak pressures were $18.83,20.05,22.73,24.67,25.73$, and $27.94 \mathrm{MPa}$, respectively. The relationship between breakdown energy and shock-wave peak pressure showed the same trend for other hydrostatic pressures. Therefore, it was not analyzed again in this study.

4.1.2. Influence of Hydrostatic Pressure $\left(P_{w}\right)$ on Shock-Wave Pressure Characteristics. The influence of hydrostatic pressure on shock-wave generation by discharge in water has been rarely mentioned in previous studies. Existing systematic experiments were also insufficient. Therefore, the influence of hydrostatic pressure on shock waves was a focus of this study. As shown in Figure 9, when the charging voltage was fixed, the shock-wave peak pressure first increased and then decreased as the hydrostatic pressure increased from $0 \mathrm{MPa}$ to $8 \mathrm{MPa}$. Within this range, the shock-wave peak pressure increased rapidly as the hydrostatic pressure increased from $0 \mathrm{MPa}$ to $1 \mathrm{MPa}$ and then increased gently from 1 to $3 \mathrm{MPa}$. The shock-wave peak pressure reached the maximum when the hydrostatic pressure was $3 \mathrm{MPa}$; after this, it decreased gradually as the hydrostatic pressure rose from 3 to $8 \mathrm{MPa}$. 
The major reason for this trend was hydrostatic pressure. The increase in hydrostatic pressure influences the shock wave in two ways: (1) the influence of hydrostatic pressure on the discharge breakdown effect: as previously mentioned, the increase in hydrostatic pressure resulted in an inhibiting effect of the water dielectric on plasma channel formation; consequently, the breakdown time increased and the breakdown energy decreased, which had an inhibiting effect on shock-wave peak pressure; (2) because the distance between number 1 sensor and the electrode was $0.5 \mathrm{~m}$, the shockwave transfer was affected by hydrostatic pressure. For weak shock waves (with peak pressure less than $100 \mathrm{MPa}$ ), the transfer process and characteristics were similar to those of sound waves in water. At room temperature, the velocity and peak pressure of shock waves with the same distance to the source also increased with increasing water pressure. Shockwave attenuation was weakened due to the increase in water density. As a result, the increase in hydrostatic pressure had a promoting effect on shock-wave transfer.

Shock-wave peak pressure reached the maximum at a hydrostatic pressure of $3 \mathrm{MPa}$ in this study. The shockwave peak pressure showed an increasing trend when the hydrostatic pressure was in the range of $0-3 \mathrm{MPa}$. This range was defined as the increasing range. As the hydrostatic pressure increased from $4 \mathrm{MPa}$ to $8 \mathrm{MPa}$, the shock-wave peak pressure showed a decreasing trend, and therefore this range was called the decreasing range.

In the increasing range, the breakdown effect was not greatly affected by hydrostatic pressure due to the low water pressure and the presence of small bubbles. The breakdown energy $\left(E_{b}\right)$ decreased slightly. The increase in hydrostatic pressure enhanced energy transfer, and the inhibiting effect of hydrostatic pressure was less than the transfer-promoting effect. As a result, the shock-wave peak pressure increased with increasing hydrostatic pressure. When the hydrostatic pressure increased from 0 to $1 \mathrm{MPa}$ (i.e., from no water pressure to some water pressure), the shock-wave peak pressure increased greatly. It was obvious that the transfer-promoting effect played a dominant role, whereas the inhibiting effect of hydrostatic pressure could be ignored with increasing hydrostatic pressure in low-pressure environments.

When the hydrostatic pressure exceeded one critical value (the critical value was about 3-4 MPa in this study), the original small bubbles in the water disappeared. Breaking down the water dielectric was no longer easy, and therefore this range was called the decreasing range. The breakdown time and the energy leakage increased, causing an inhibiting effect on breakdown. As a result, the breakdown $\left(E_{b}\right)$ decreased greatly. Moreover, the higher the hydrostatic pressure is, the more obvious the inhibiting effect became. In this process, although the increase in hydrostatic pressure could enhance shock-wave transfer, the promoting effect was limited. The inhibiting effect of hydrostatic pressure was obviously greater than the transfer-promoting effect. Therefore, the shockwave peak pressure decreased gradually with increasing hydrostatic pressure.
4.2. Attenuation Law of Shock Waves during Propagation. Shock-wave attenuation in water is caused by two main factors: (1) the shock heating and damping effect of shock-wave energy on water: the shock-wave strength showed exponential attenuation in the transfer process; (2) during the evanescent expansion and constriction of pulsation bubbles, the rarefaction wave from the bubble surface showed an unloading effect on formation of the shock-wave tail. Because the expansion velocity of bubble pulsations in the high-voltage discharge was very slow, it had little influence on shock-wave attenuation. Therefore, bubble action was not considered here. In this study, shock-wave attenuation during propagation was investigated under different discharge energy and hydrostatic pressure conditions.

The empirical equation (6) basically reflects the propagation law of shock waves in a single hydrostatic-pressure environment. However, it has certain limitations because the influence of hydrostatic pressure on shock-wave transfer is not included. According to the shock-wave theory proposed by Chapman [22], an approximate formula for propagation of shock waves in water can be written as

$$
P=k \cdot d^{\beta} \cdot E_{b}^{\alpha}
$$

where $P$ is the shock-wave peak pressure; $d$ is the distance from the electrode to the sensor, $\mathrm{mm}$; and $E_{b}$ is the breakdown voltage during discharge. The coefficient $k$ depends on hydrostatic pressure. $\alpha$ and $\beta$ are shock-wave transfer coefficients that are affected by hydrostatic pressure. Of these, $\alpha$ is mainly targeted at breakdown energy $\left(E_{b}\right)$, whereas $\beta$ is mainly targeted at shock-wave propagation distance $(d)$. Fitted results for hydrostatic pressures of $0,1,2,3,4,6$, and $8 \mathrm{MPa}$ are shown in Figure 10. The figure could not be well read after adding error bars due to severe overlapping. Moreover, the error bars of data had little influence on the analysis in this study. Therefore, the error bars in Figure 10 were removed.

The values of $k, \alpha$, and $\beta$ in (7) were fitted using experimental data. An obvious change law with increasing hydrostatic pressure could be found. The values of $k, \alpha$, and $\beta$ under different hydrostatic pressure conditions are shown in Figure 11 .

The parameters $k, \alpha$, and $\beta$ exhibit typical exponential attenuation or increase characteristics with increasing hydrostatic pressure. Therefore, function curves of $k, \alpha$, and $\beta$ against hydrostatic pressure were fitted. The black, blue, and red lines represent $k, \alpha$, and $\beta$, respectively. The functions giving $k, \alpha$, and $\beta$ against hydrostatic pressure can be expressed approximately as follows:

$$
\begin{aligned}
& k=7.23+30.46 \exp ^{-P_{w} / 2.67}, \\
& \alpha=0.46-0.14 \exp ^{-P_{w} / 1.75}, \\
& \beta=-0.32-0.17 \exp ^{-P_{w} / 4.70} .
\end{aligned}
$$

The function expressions above can be substituted into (7), yielding a function relating shock-wave peak pressure $(P)$ to 

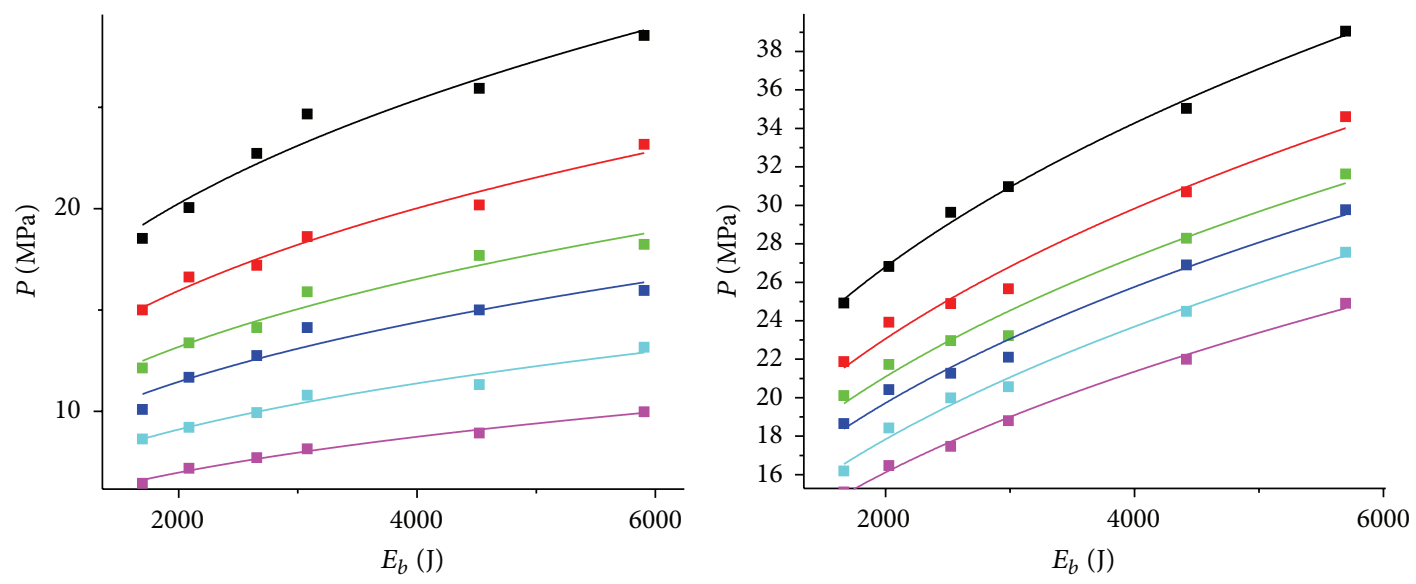

$P_{w}=0 \mathrm{MPa}$

- $d=0.5 \mathrm{~m}$

- $d=1 \mathrm{~m}$

- $d=2 \mathrm{~m}$

- $d=1.5 \mathrm{~m}$

- $d=2.5 \mathrm{~m}$

- $d=3 \mathrm{~m}$

$$
\begin{aligned}
& P_{w}=1 \mathrm{MPa} \\
& \text { - } d=0.5 \mathrm{~m} \\
& \text { - } d=1 \mathrm{~m} \\
& \text { - } d=2 \mathrm{~m} \\
& \text { - } d=1.5 \mathrm{~m} \\
& \square=2.5 \mathrm{~m} \\
& \text { - } d=3 \mathrm{~m}
\end{aligned}
$$
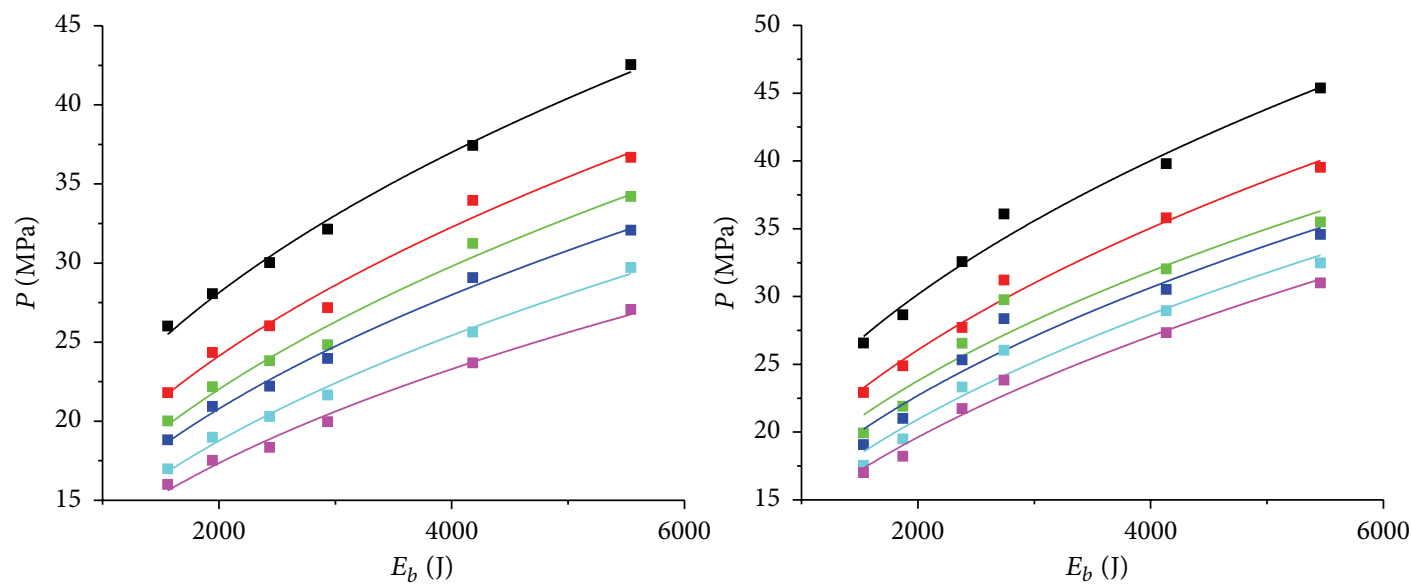

$$
\begin{array}{ll}
P_{w}=2 \mathrm{MPa} & \\
\square d=0.5 \mathrm{~m} & \square d=2 \mathrm{~m} \\
\square d=1 \mathrm{~m} & \square d=2.5 \mathrm{~m} \\
\square d=1.5 \mathrm{~m} & \square d=3 \mathrm{~m}
\end{array}
$$

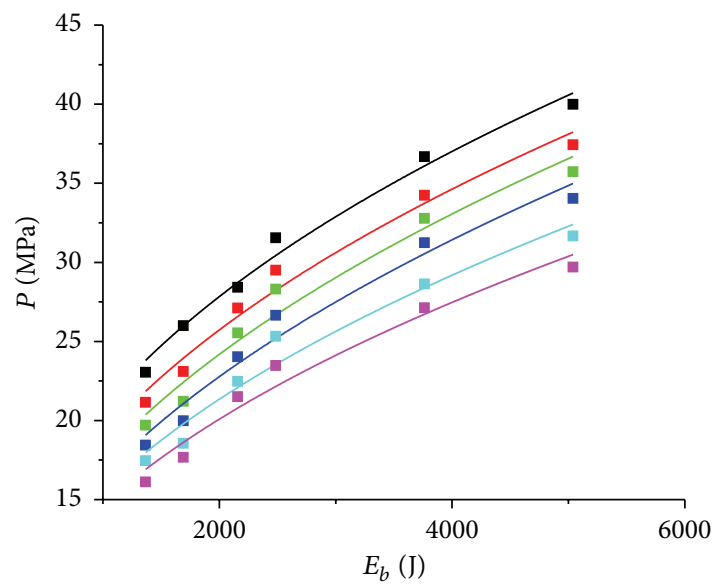

$$
\begin{aligned}
& P_{w}=3 \mathrm{MPa} \\
& \text { - } d=0.5 \mathrm{~m} \\
& \text { - } d=1 \mathrm{~m} \\
& \text { - } d=1.5 \mathrm{~m} \\
& \text { - } d=2 \mathrm{~m} \\
& \text { - } d=2.5 \mathrm{~m}
\end{aligned}
$$

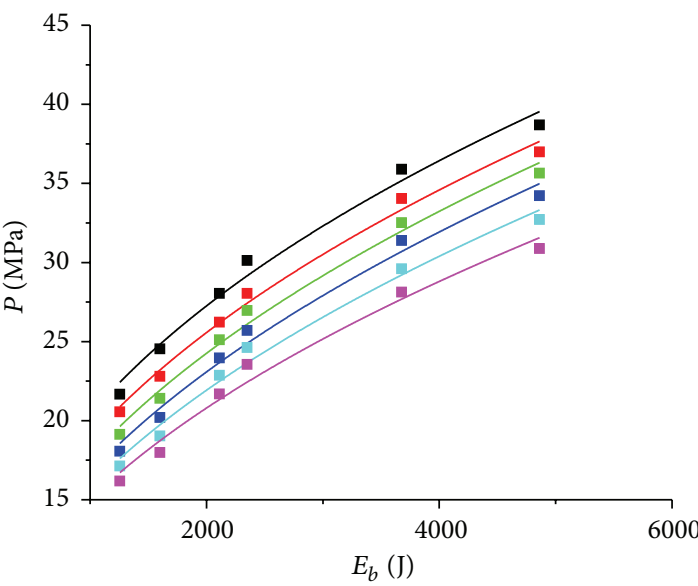

$P_{w}=4 \mathrm{MPa}$

$$
\begin{aligned}
\text { - } d & =0.5 \mathrm{~m} \\
\text { - } d & =1 \mathrm{~m}
\end{aligned}
$$

- $d=2 \mathrm{~m}$

- $d=1.5 \mathrm{~m}$

- $d=2.5 \mathrm{~m}$

- $d=3 \mathrm{~m}$

$P_{w}=6 \mathrm{MPa}$

- $d=0.5 \mathrm{~m}$

- $d=1 \mathrm{~m}$

$d=1.5 \mathrm{~m}$

- $d=2 \mathrm{~m}$

$d=2.5 \mathrm{~m}$

- $d=3 \mathrm{~m}$

Figure 10: Continued. 


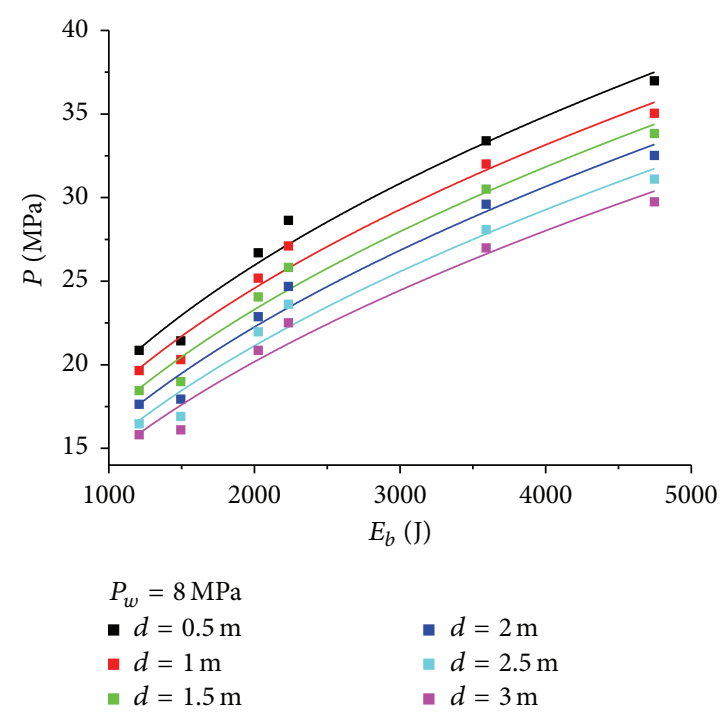

FIGURE 10: Relationship between breakdown energy $\left(E_{b}\right)$ and shock-wave peak pressure for different transfer distances and hydrostatic pressures.

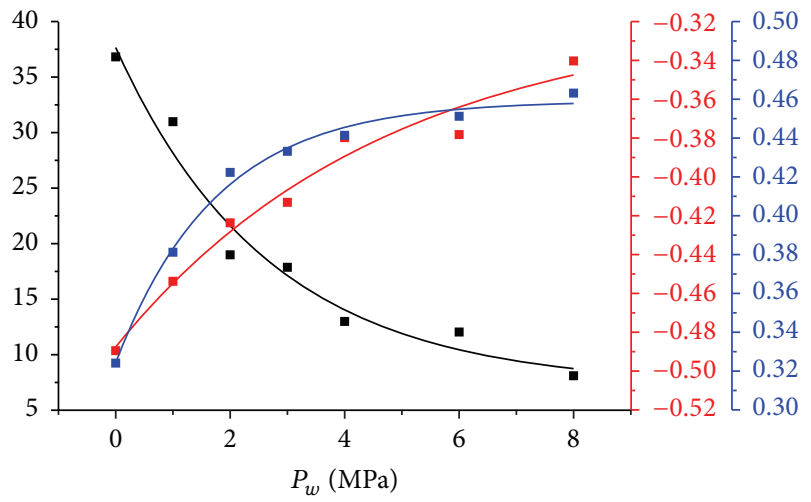

- $k$
- $\beta$
- $\alpha$

FIGURE 11: Values and fitted curves of $k, \alpha$, and $\beta$.

breakdown energy $E_{b}(\mathrm{~J})$, hydrostatic pressure $P_{w}(\mathrm{MPa})$, and transfer distance $d(\mathrm{~mm})$ :

$$
\begin{aligned}
P= & \left(7.23+30.46 \exp ^{-P_{w} / 2.67}\right) \cdot d^{-0.32-0.17 \exp ^{-P_{w} / 4.70}} \\
& \cdot E_{b}^{0.46-0.14 \exp ^{-P_{w} / 1.75}} \cdot
\end{aligned}
$$

The approximate formula (9) is an approximate fitting equation for the propagation of shock waves in water. In this study, two groups of experimental parameter values were selected to verify (9): hydrostatic pressure $P_{w}=5 \mathrm{MPa}$ and charging voltage $U_{m}=12 \mathrm{KV}$; and hydrostatic pressure $P_{w}=9 \mathrm{MPa}$ and charging voltage $U_{m}=7 \mathrm{KV}$. The data for the first test $\left(P_{w}=5 \mathrm{MPa}\right.$ and $\left.U_{m}=12 \mathrm{KV}, E_{b}=3020 \mathrm{~J}\right)$ were distributed within the original scope of the experimental parameters, whereas the data for the second test $\left(P_{w}=9 \mathrm{MPa}\right.$ and $U_{m}=$ $\left.7 \mathrm{KV}, E_{b}=970 \mathrm{~J}\right)$ were outside the original experimental

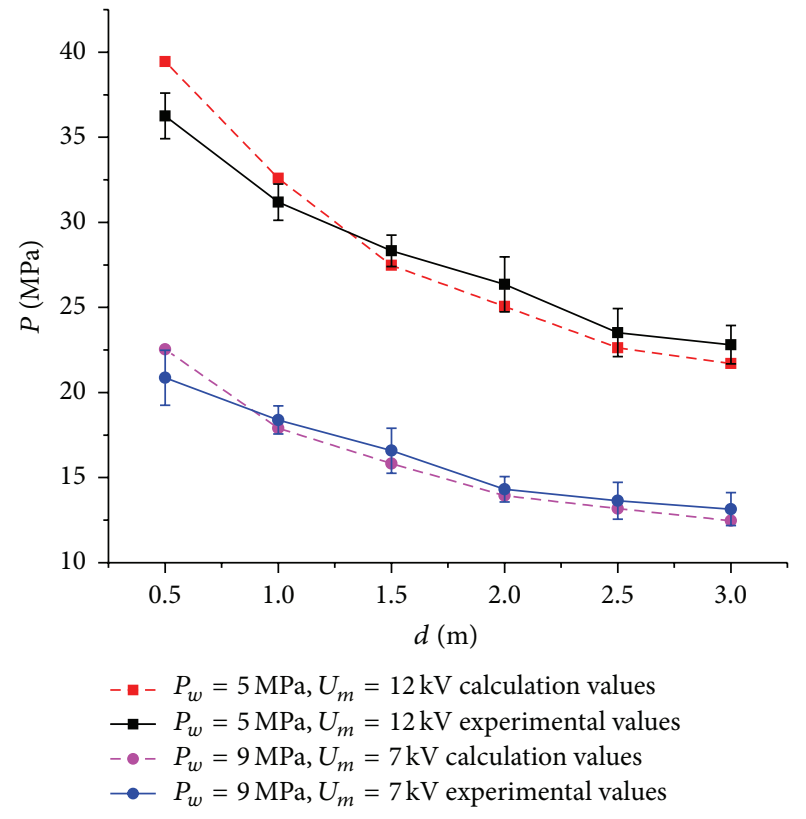

Figure 12: Comparison between new experimental values and calculated values.

parameter scope. The experimental values and the values calculated according to (9) were compared, with the results shown in Figure 12.

The experimental and calculated values in Figure 12 were close to each other. Moreover, the attenuation trend of shock-wave peak pressure with increasing propagation distance was similar to results reported earlier. Compared to the empirical equation (6) for shock-wave peak pressure in previous studies, the influence of hydrostatic pressure on shock-wave attenuation during propagation was fully considered in (9). Therefore, the fitted results were closer to 
actual conditions. The fitting range was enlarged from the original low hydrostatic pressure (within $0.1 \mathrm{MPa}$ ) to high hydrostatic pressure (within $10 \mathrm{MPa}$ ).

According to the experimental results and the approximate propagation formula for shock waves in water, the attenuation of shock waves formed by high-voltage pulse discharge in water was found to conform to the following laws.

The higher the breakdown energy of the shock wave formed, the lower the shock-wave attenuation during propagation. This clearly demonstrated the influence of shockwave energy on shock-wave pressure during propagation. The shock-wave energy could make up for the loss of wavehead energy, and therefore higher shock-wave energy was advantageous to attaining high shock-wave pressures during propagation. This case was consistent with the explosion theory in water proposed by Cole [23].

The attenuation of the shock wave slowed down gradually with increasing hydrostatic pressure. As the hydrostatic pressure increased to a certain value, the attenuation trend of the shock wave gradually leveled off. The attenuation rate was further reduced when the distance between the shock wave and the electrode reached a certain value. Therefore, high hydrostatic pressure was advantageous to shock-wave propagation. Moreover, it effectively enhanced the scope of influence of the shock wave. This phenomenon was approximated using the explosion shock-wave theory in water proposed by Kochetkov and Pinaev [24]. The results were consistent with the hydrostatic-pressure theoretical analysis of shock-wave pressure characteristics at $0.5 \mathrm{~m}$, as described earlier.

\section{Conclusions}

(1) The breakdown of a water dielectric by a highvoltage pulse discharge was found to be similar to the explosion process, which is affected by voltage and hydrostatic pressure. If the discharge voltage was increased, the breakdown delay in the discharge process decreased, the resistance of the plasma channel decreased, the energy input into the channel increased, and the peak pressure of the formed shock wave increased. If the hydrostatic pressure was increased, formation of the plasma channel was restricted by external water pressure; in addition, the breakdown delay and the channel resistance increased, hindering the discharge breakdown process.

(2) The shock-wave peak pressure at $0.5 \mathrm{~m}$ was directly affected by the discharge breakdown energy of the water dielectric. The higher the energy, the higher the shock-wave peak pressure. When the hydrostatic pressure was increased from 0 to $8 \mathrm{MPa}$, the shock-wave peak pressure first increased and then decreased. The shock-wave peak pressure increased when the hydrostatic pressure was in the range of $0-3 \mathrm{MPa}$ and reached the maximum value at $3 \mathrm{MPa}$; it then decreased gradually when the hydrostatic pressure was in the range of 3-8 $\mathrm{MPa}$.
(3) During the shock-wave transfer process, the higher the breakdown energy, the lower the shock-wave attenuation. The shock-wave attenuation slowed down gradually with increasing hydrostatic pressure, which was advantageous to stable shock-wave transfer. With increasing propagation distance, the stabilizing effect of hydrostatic pressure on the shock wave became more and more obvious. An approximate formula (i.e., (9)) for propagation of shock waves in water with different hydrostatic pressures was fitted based on mass data. The relationship between shock-wave transfer attenuation in water and energy, hydrostatic pressure, and propagation distance was quantified.

\section{Competing Interests}

The authors declare that there is no conflict of interests regarding the publication of this paper.

\section{Acknowledgments}

This work is supported by the Shanxi Coalbed Methane Foundation of China (2012012012).

\section{References}

[1] Q. Yong, A. C. Qiu, and Y. M. Zhang, "Experiment and discovery on permeability improved technology of coal reservoir based on repeated strong pulse waves of high energy accumulation," Coal Science and Technology, vol. 42, no. 6, pp. $1-7,2014$.

[2] O. Maurel, T. Reess, M. Matallah et al., "Electrohydraulic shock wave generation as a means to increase intrinsic permeability of mortar," Cement and Concrete Research, vol. 40, no. 12, pp. 1631-1638, 2010.

[3] H. Akiyama, "Streamer discharges in liquids and their applications," IEEE Transactions on Dielectrics and Electrical Insulation, vol. 7, no. 5, pp. 646-653, 2002.

[4] I. Z. Okun, "Plasma parameters in a pulsed discharge in a liquid," Soviet Physics: Technical Physics, vol. 16, no. 2, pp. 227231, 1971.

[5] P. Cole, Underwater Explosion, National Defence Industry Press, Beijing, China, 1960.

[6] I. Z. Okun, "Generation of compression waves by a pulsed discharge in water," Soviet Physics-Technical Physics, vol. 16, no. 2, pp. 219-226, 1971.

[7] B. R. Locke, M. Sato, P. Sunka, M. R. Hoffmann, and J. Chang, "Electrohydraulic discharge and nonthermal plasma for water treatment," Industrial \& Engineering Chemistry Research, vol. 45, no. 3, pp. 882-905, 2006.

[8] J. S. Chang, K. Urashima, and Y. Uchida, "Characteristics of pulsed arc electrohydraulic discharges and their application to water treatment," Research Reports of Tokyo Denki University, no. 50, p. 1, 2002.

[9] X. L. Yao, Y. Wang, and A. M. Zhang, Underwater Explosion Bubble Dynamics, Harbin Engineering University Press, Harbin, China, 2011.

[10] Z. H. Zeng, Research of Large Pulsed Current Test, Nanjing University of Science and Technology, Nanjing, China, 2006. 
[11] Y. S. Liu, "Method of using P6015A detection head to measure DC high voltage," Electrotechnics Electric, vol. 4, no. 1, pp. 42-44, 2006.

[12] R. M. Roberts, J. A. Cook, R. L. Rogers, A. M. Gleeson, and T. A. Griffy, "The energy partition of underwater sparks," Journal of the Acoustical Society of America, vol. 99, no. 6, pp. 3465-3475, 1996.

[13] J. W. Robinson, "Finite-difference simulation of an electrical discharge in water," Journal of Applied Physics, vol. 44, no. 1, pp. 76-81, 1973.

[14] H. H. Zhang, Z. F. Chen, and X. P. Lu, "Measurement system in underwater wire exploding process," Journal of Test and Measurement Technology, vol. 14, no. 4, pp. 221-225, 2000.

[15] X. P. Lu, Y. Pan, and H. H. Zhang, "The electrical and acoustical characteristics of pulsed discharge in water," Chinese Journal of Physics, vol. 51, no. 7, pp. 50-54, 2002.

[16] B. Sun, Discharge Plasma in Liquid and Its Applications, Science Press, Beijing, China, 2013.

[17] Z. Y. Qin, G. N. Zuo, Y. R. Wang, G. S. Sun, and Y. H. Sun, High-Voltage Strong-Pulse Discharge and Its Applications, Beijing University of Technology Press, Beijing, China, 2000.

[18] D. B. Fenneman and R. J. Gripshover, "Experiments on electrical breakdown in water in the microsecond regime," IEEE Transactions on Plasma Science, vol. 8, no. 3, pp. 209-213, 1980.

[19] S. M. Korobeinikov, Bubble model of ignition of the impulse electric discharge in liquids [Ph.D. thesis], Tomsk Polytechnic University, Tomsk, Russia, 1998.

[20] W. Jia, A. C. Qiu, F. Sun, and J. Guo, "Effects of the pressure under the several hundred nanosecond pulse on the breakdown characteristics of the water switch," High Voltage Engineering, vol. 32, no. 1, pp. 50-52, 2006.

[21] G. Touya, T. Reess, L. Pécastaing et al., "Development of subsonic electrical discharges in water and measurements of the associated pressure waves," Journal de Physique D: Applied Physics, no. 39, pp. 5236-5244, 2006.

[22] N. R. Chapman, "Measurement of the waveform parameters of shallow explosive charges," The Journal of the Acoustical Society of America, vol. 78, no. 2, p. 672, 1985.

[23] R. H. Cole, Underwater Explosions, Princeton University Press, Princeton, NJ, USA, 1948.

[24] I. I. Kochetkov and A. V. Pinaev, "Shock-wave processes in wire explosion in water and bubbly media," Combustion, Explosion, and Shock Waves, vol. 51, no. 6, pp. 722-731, 2015. 


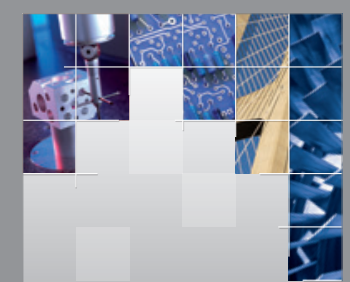

\section{Enfincering}
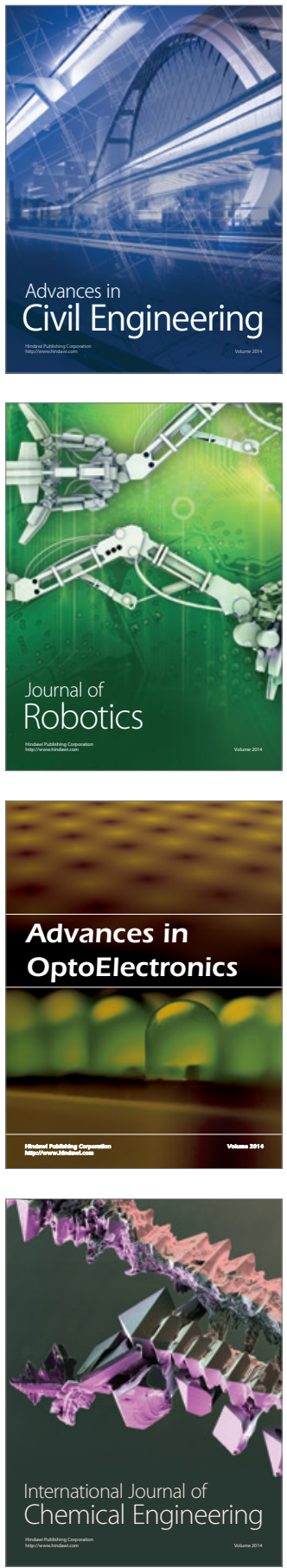

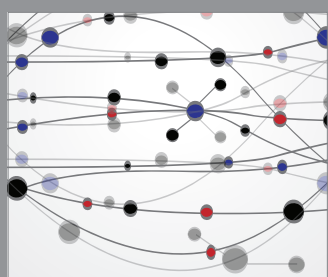

The Scientific World Journal

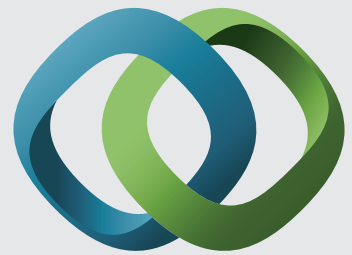

\section{Hindawi}

Submit your manuscripts at

http://www.hindawi.com
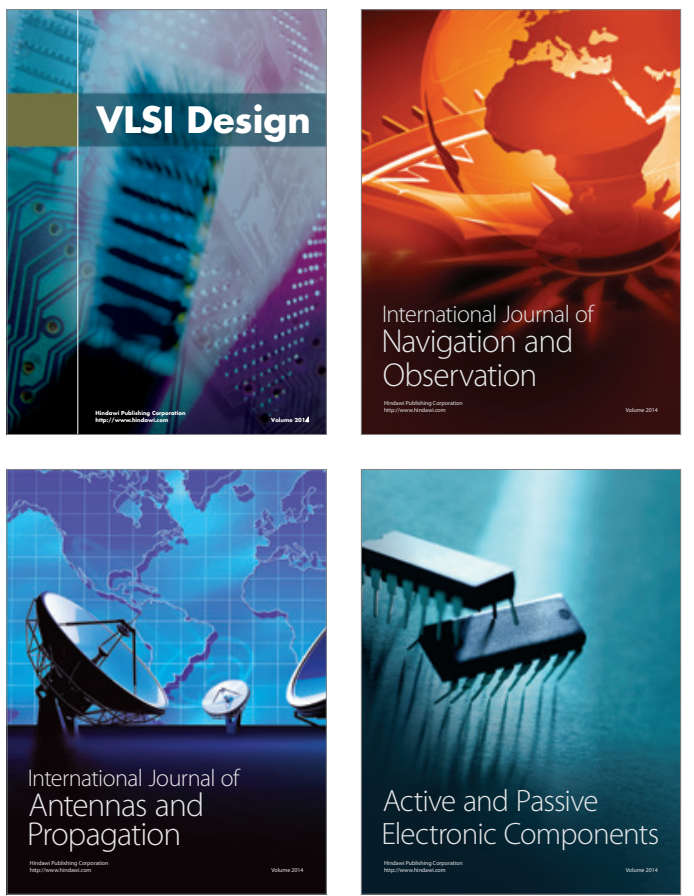
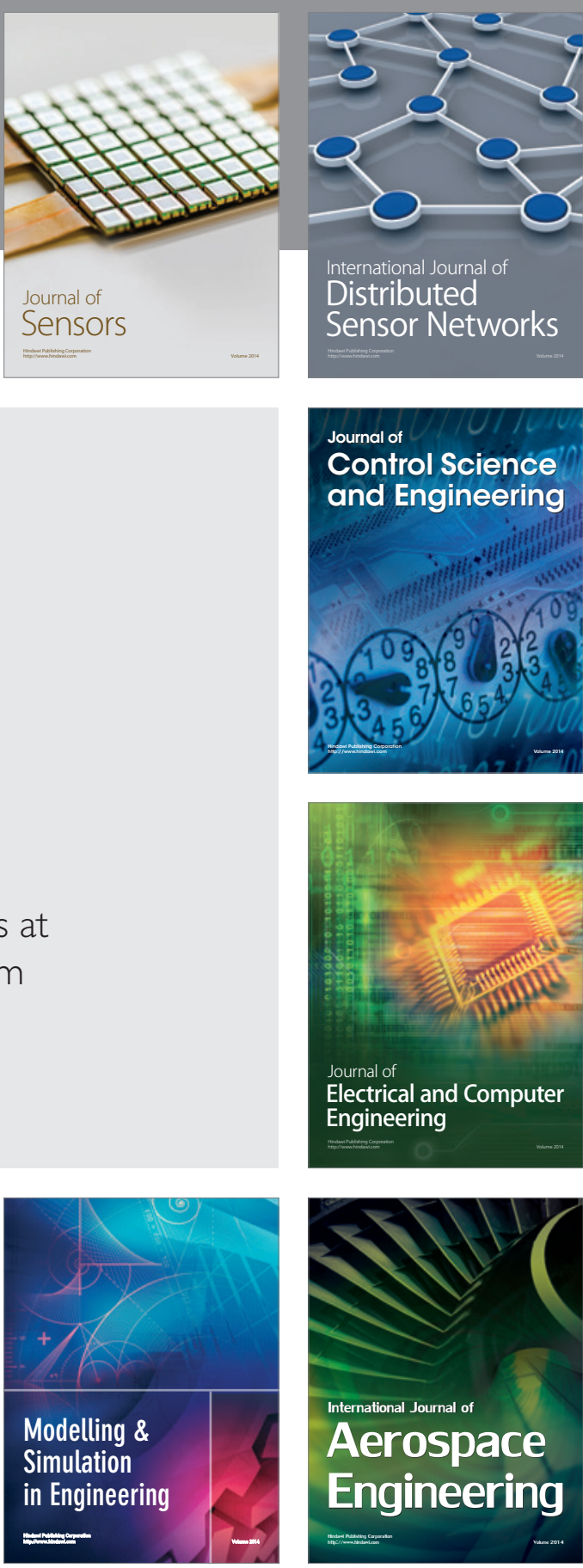

International Journal of

Distributed

Sensor Networks

Journal of

Control Science

and Engineering
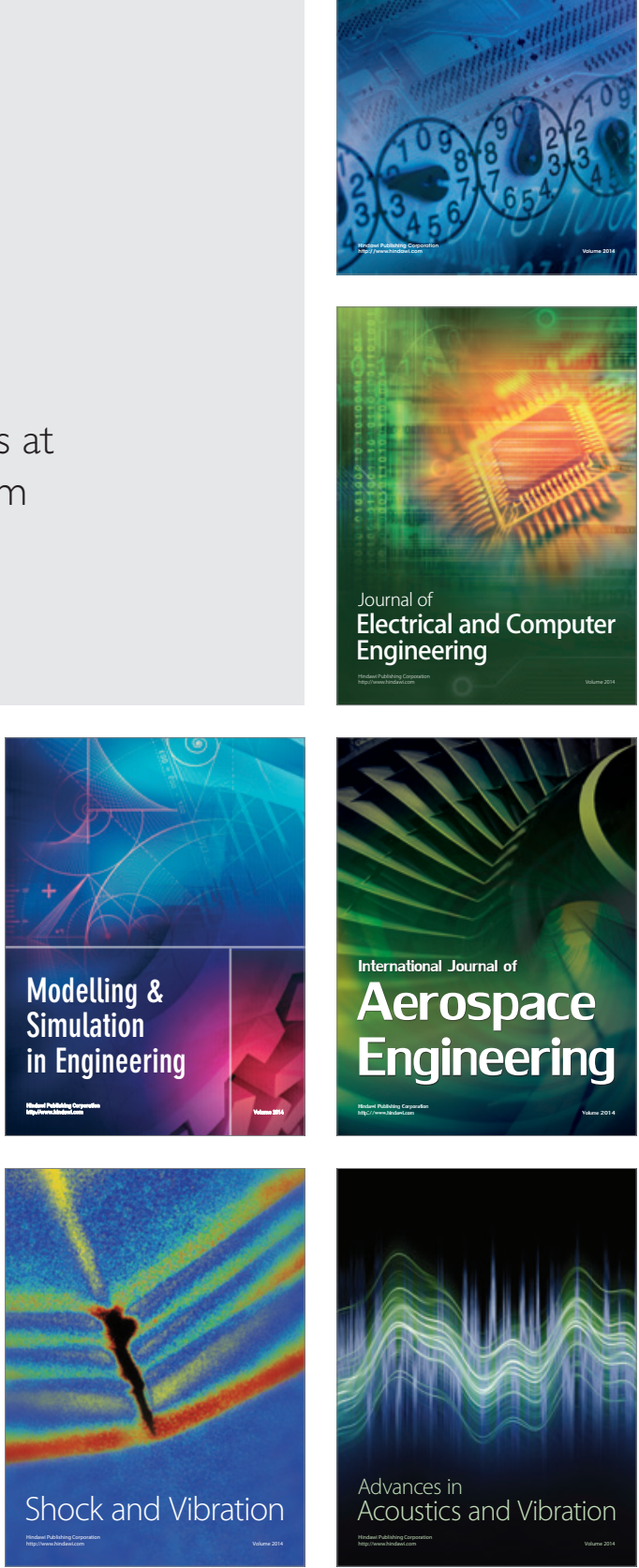